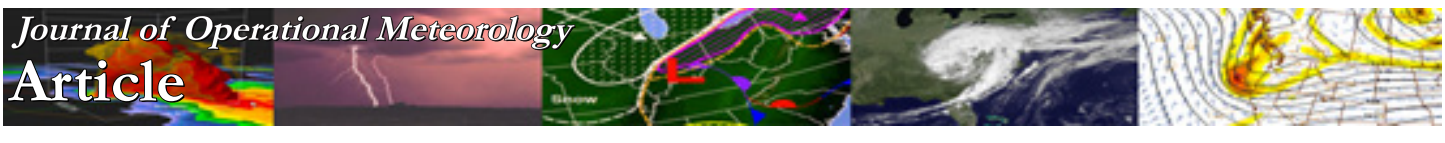

\title{
Techniques and Thresholds of Significance for Using WSR-88D Velocity Data to Anticipate Significant Tornadoes
}

\author{
JUSTIN G. GIBBS \\ NOAA/NWS Warning Decision Training Division, Norman, Oklahoma \\ BARRY R. BOWERS \\ NOAA/NWS Forecast Office, Norman, Oklahoma
}

(Manuscript received 16 October 2018; review completed 6 May 2019)

\begin{abstract}
Significant tornadoes $(\mathrm{EF} 2+)$ make up a very small percentage of the total United States tornado events, but produce the overwhelming majority of tornado fatalities. Identifying significant tornado events in a shortfused warning environment has been a particular focus of the United States National Weather Service's severe weather program in recent years, with the goal of reducing the loss of life from significant events to the greatest extent possible.

This study aims to further this effort by identifying and quantifying the skill of key signals present in Weather Service Radar-1998 Doppler velocity data in the minutes prior to the onset of significant tornado damage. When separated by storm mode, several radar velocity signals are identified that show operationally useful skill in differentiating between significant and weak/nontornadic events in supercells-with lead time. The highest skill scores are achieved by combining maximum volumetric rotational speed and depth of the storm's mesocyclone, as well as the overall change in rotational speed in the final minutes prior to the onset of significant damage. Very little, if any, predictive skill was found when only the lowest elevation scan was considered, including more frequent supplementary scans in between full volumetric scans. The same signals that showed noteworthy skill for supercells failed to discriminate between significant and weak/nontornadic events in quasi-linear convective Systems and bow echo/mesoscale convective vortex events.
\end{abstract}

\section{Introduction}

Significant tornadoes (EF2+ on the Enhanced-Fujita Scale, www.spc.noaa.gov/efscale/ef-ttu.pdf) made up $11.7 \%$ of all tornado events in the United States from 2008 through the summer of 2018 (www.ncdc.noaa. gov/stormevents/), but produced $96 \%$ of all tornado fatalities in that same period (www.spc.noaa.gov/climo/ torn/fatalmap.php). The National Weather Service (NWS) is tasked to provide warnings for all tornado events, regardless of intensity. Following the deadly Joplin, Missouri, tornado of 22 May 2011, a concerted effort has been made by the NWS to provide enhanced language in warnings for significant tornadoes via the implementation of impact-based warnings (IBWs, NWS 2019a).
IBWs are utilized for all severe convective hazards. Impact-based tornado warnings are categorized based on what is known about the presence of a tornado, and what can be ascertained about the tornado's damage production (www.weather.gov/impacts). Through IBWs, NWS forecasters can select from different categories of warnings appropriate for the given situation, such as a (1) "tornado possible" notification within a severe thunderstorm warning when forecaster confidence does not warrant a tornado warning (NWS 2019b), (2) "base" tornado warning, which provides information about the threat and general protective action recommendations, (3) "considerable" category, which invokes more vivid descriptions of potentially significant damage with a higher degree of certainty in the language, and (4) "catastrophic" category,

Corresponding author address: Justin Gibbs, 120 David L. Boren Blvd. Ste 2640 Norman, OK 73072

E-mail: justin.gibbs@noaa.gov 
which enables the forecast office to declare a "tornado emergency" for a given area within the tornado warning.

The language within IBW tornado warnings has undergone significant revision from its initial introduction in 2011 to its nationwide implementation in spring 2016. This revision was made possible by considerable internal effort, as well as academic research. For example, Ripberger et al. (2015) provided evidence that the language used in IBWs would make those in the path of a tornado more likely to take appropriate protective action. However, the study also found that once the language reaches a certain threshold, bolder and more vivid statements do not improve response, and may increase tendencies for those in danger to not seek shelter as they feel the danger is too great for their efforts to be effective in providing protection. The NWS brought the wording of the "considerable" and "catastrophic" warning categories closer together following this assessment. Casteel $(2016,2018)$ showed that the similar language of the considerable and catastrophic IBWs still was fully effective in encouraging appropriate response and protective action. In general, more specific messaging in warning statements is shown to increase rates of appropriate protective action (Naegle and Trainor 2012).

The scenarios for proper use of these tags are governed by NWS directives (NWS 2019b), and scenario training is provided by the NWS Warning Decision Training Division (WDTD 2018b). There are a number of conditions and permutations possible under IBWs, and the formal directive provides forecasters with some degree of latitude on what constitutes appropriate situations for each warning. WDTD training specifies that "base" tornado warnings are for situations where the intensity is unknown, or the tornado is currently analyzed to be below the significant intensity threshold (i.e., EF0 or EF1). The considerable category is to be used when there is reasonably strong evidence that an EF2+ tornado is in progress or imminent. The catastrophic category is for situations where a tornado has been confirmed, either visually or via radar, and the tornado is expected to be significant $(\mathrm{EF} 2+)$ and strike a populated area (WDTD 2018b).

This process is based on a decades-long foundation of scientific research [e.g., the initial discovery by Brown et al. (1978) of tornadic vortex signatures (TVSs) in velocity data from Doppler radars]. Our understanding of severe thunderstorm and supercell structure and the role of the mesocyclone in tornadogenesis was further refined by Lemon and Doswell (1979). This was followed by numerous techniques that were developed for using the Weather Service Radar-1998 Doppler (WSR-88D) - following its national implementationfor issuing tornado warnings (Falk 1997).

Efforts to rapidly infer the intensity of an ongoing or imminent tornado from Doppler velocity data build on the work of Burgess et al. (2002). Brown et al. (2002) published results showing that a reduction of the effective beamwidth of the WSR-88D significantly improved the resolution of radar signatures. This led to the implementation of so-called super-resolution Doppler velocity data $\left(0.5^{\circ}\right.$ azimuth $\times 250 \mathrm{~m}$ range gates) that allowed for better discrimination of stronger velocity signals that are associated with stronger tornadoes.

This new capability and the need for a deeper body of physical science to properly execute IBWs have led to a surge of studies specifically focusing on diagnosing current tornado intensity based on WSR88D data. Toth et al. (2013) published initial research suggesting that such discrimination was possible. Kingfield and LaDue (2015) were among the first to specifically focus on IBW execution, and determined that automated mesocyclone detections provided the highest skill scores in discriminating between weak (EF0 and EF1) and significant (EF2+) tornadoes at rotational velocity $\left[V_{\text {rot }}=\left(V_{\max }-V_{\min }\right) / 2\right)$, where $V_{\max }$ is the maximum outbound wind speed and $V_{\min }$ is the most negative (i.e., inbound) wind speed] values between 18 and $25.72 \mathrm{~m} \mathrm{~s}^{-1}$ (35 and $50 \mathrm{kt}$ ). There was considerable overlap between weak and significant tornado events, but overall the skill scores were comparable to the skill in differentiating between tornadic and nontornadic signatures.

Smith et al. (2015, hereafter S15) significantly advanced the process, evaluating the probability of a damage report at a given EF-scale rating based on observed maximum $V_{\text {rot }}$ values during the event as well as environmental conditions as expressed by the significant tornado parameter (Thompson et al. 2012). This study showed the ability to discriminate tornado intensity was significantly limited at ranges $>120-129.6 \mathrm{~km}(65-70 \mathrm{n} \mathrm{mi})$ from a WSR-88D site, which agrees with principles discussed by Dowell et al. (2005), Wood and Brown (1997), and Dahl and Nolan (2018). Thompson et al. (2017, hereafter T17) followed up on this work by increasing the dataset to include a robust sample of nontornadic severe thunderstorms, with an increased focus on reducing estimation errors 
as a result of WSR-88D data quality issues like vertical sidelobe contamination, which has proven to be a significant challenge when trying to use the radar as precisely as tornado intensity estimation requires. Cohen et al. (2018) summarized many of these findings into statistical models designed to diagnose tornado intensity in real-time.

This body of work was converted to use in NWS operations through WDTD training and the IBW course (WDTD 2018b). Gibbs (2016, hereafter G16) evaluated the skill of guidance provided in that training, combining $V_{\text {rot }}$ and tornadic debris signature (TDS) characteristics to find optimum thresholds for skill in differentiating between weak and significant tornadoes in real-time. The study also examined multiple volumetric radar datasets prior to the onset of both weak and significant tornadoes to identify characteristics that differentiated, with some degree of lead time, between weak and significant tornadoes.

The present study is a follow-up to that work, using a larger dataset (290 cases total) to attempt to identify radar characteristics that differentiate between weak and significant tornado events at up to four volume scans (VSs) prior to the onset of significant damage. This would result in lead times of up to 20-23 min, depending on the exact mode the radar is operating in (WDTD 2018d). This study expands upon the predictive portion of G16 by including a sample of severe but nontornadic supercells and quasi-linear convective system (QLCS) events gathered, in part, from the database of tornado and significant severe weather events utilized in S15 and T17. The emphasis is not necessarily on identifying storm-scale processes that lead to the development of significant tornadoes, but rather on discerning cues in operational data that can be acted upon in real-time to make decisions. The analysis is separated by storm mode into supercell and QLCS events. Supercell events include embedded supercell clusters, cell in line, miniature supercells, and discrete supercells (Smith et al. 2012). QLCS events include bow echoes, linear systems, and mesoscale convective vortices (MCVs; Thompson et al. 2012).

\section{Data and methods}

\section{a. Case selection and quality control methods}

Significant tornado events were identified using the National Centers for Environmental Information (NCEI) storm events database (www.ncdc.noaa. gov/stormevents/) and published NWS tornado damage surveys (apps.dat.noaa.gov/stormdamage/ damageviewer/). Cases were selected from January through March 2019. The cases were limited to events that occurred within $138.9 \mathrm{~km}$ (75 $\mathrm{n} \mathrm{mi})$ of a WSR-88D site that had archive data available. From January to October 2017, every significant tornado instance was included that met quality control and distance-fromradar requirements. This resulted in 65 supercell and 47 QLCS tornado events. An additional 20 supercell and 13 QLCS tornado cases were selected from the first five months of 2018 and 2019 as events occurred that met storm-mode, data quality, and range-from-radar requirements-leading to a total of 85 supercell and 60 QLCS significant tornado events. This kept the ratio of supercell to QLCS events similar to what had been randomly sampled during most of 2017. Nonsignificant tornado cases, hereafter referred to as NIL cases, comprised (i) severe but nontornadic events and (ii) EF0 and EF1 tornado events. The majority of cases (104) were identified using the S15 and T17 database containing storms that occurred in 2015. NIL cases were selected roughly based on the distribution of cases in the S15 and T17 database that comprised a majority of nontornadic cases. Therefore, nontornadic cases made up about $60 \%$ of the NIL dataset, with weak tornado events making up the remainder. Using this database allowed cases to be identified by storm mode more quickly and provided the added benefit of having already identified several NIL cases with high $V_{\text {rot }}$ values, some as high as $36 \mathrm{~m} \mathrm{~s}^{-1}(70 \mathrm{kt})$. This allowed for other defining characteristics (e.g., mesocyclone width, mesocyclone depth, and persistence) to be examined for the ability to differentiate between significant and NIL cases. Fortyone additional cases that presented relatively large $\left(\geq 15.4 \mathrm{~m} \mathrm{~s}^{-1}\right.$ or $\left.\geq 30 \mathrm{kt}\right) V_{\text {rot }}$ values were then selected from the springs of 2017-2019 to complete the dataset. The onset of significant damage was derived from the NWS Damage Assessment Toolkit (DAT, apps.dat. noaa.gov/StormDamage/DamageViewer/ ). If no DAT points were available, specific geographic references (e.g., intersections and landmarks) in the damage survey or NCEI Storm Data entry were accepted. WSR-88D data from the event then were collected and analyzed to identify the storm responsible for the reported damage.

The $0.5^{\circ}$ elevation slice from a full VS that was collected before, but closest to the DAT point indicating the start of EF2+ damage, was considered the onset point for the significant tornado cases. For example, Fig. 1 shows DAT points for an EF2 tornado that occurred 


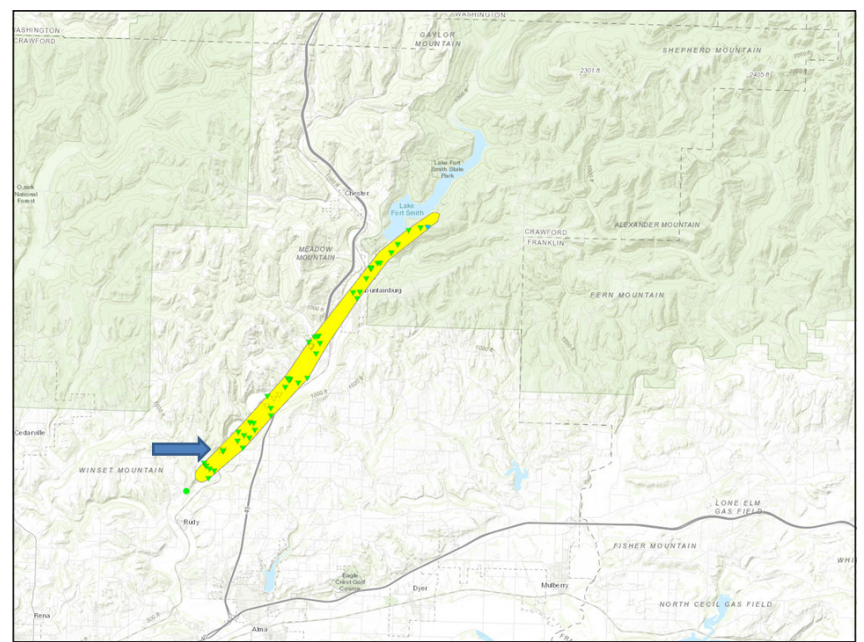

Figure 1. Tornado survey damage points in the NWS Damage Assessment Toolkit (DAT) viewer from a tornado in Crawford County, AR, on 13 April 2018. Triangles represent areas of surveyed tornado damage at (yellow) EF2, (green) EF1, and light blue EF0 intensity. The yellow area represents the total tornado path. Green circles represent areas of nontornadic wind damage. The dark blue arrow highlights the first EF2 damage near $35.56 \mathrm{~N}, 94.24 \mathrm{~W}$. Click image for an external version; this applies to all figures hereafter.

in Crawford County, Arkansas, on 13 April 2018. The first EF2 damage point is relatively close to the start of the overall tornado track in the southwestern portion of the tornado path. Information from the damage survey allowed for archived WSR-88D level II files to be matched to the onset of damage based on matching the latitude and longitude in DAT with that in GR2Analyst (www.grlevelx.com/gr2analyst 2/). Figure 2 shows an example onset point for this tornado. In nontornadic cases, the onset point was the time of maximum $V_{\text {rot }}$. In weak tornado cases, the data point best matching the onset of peak damage (either EF0 or EF1) was selected.

$V_{\text {rot }}$ was calculated similarly to methods used in S15, G16, and T17, with combinations of velocity maxima exhibiting cyclonic or anticyclonic azimuthal shear at $\leq 45^{\circ}$ opposed to one another. $V_{\text {rot }}$ was chosen from the radar slice that exhibited the largest rotational speed of the circulation $\left[\mathrm{RSC}=V_{\mathrm{rot}} /(\mathrm{d} / 2)\right]$, where $\mathrm{d}$ is the distance between the $V_{\max }$ and $V_{\min }$ pixels. Falk and Parker (1998) considered this $V_{\text {rot }}$ shear in a study that used differing methods because it predated the super-resolution WSR-88D era. Maximum RSC was selected from any circulation that subjectively appeared as a contiguous, storm-scale meteorological feature coincident with deep moist convection. This resulted in a few instances

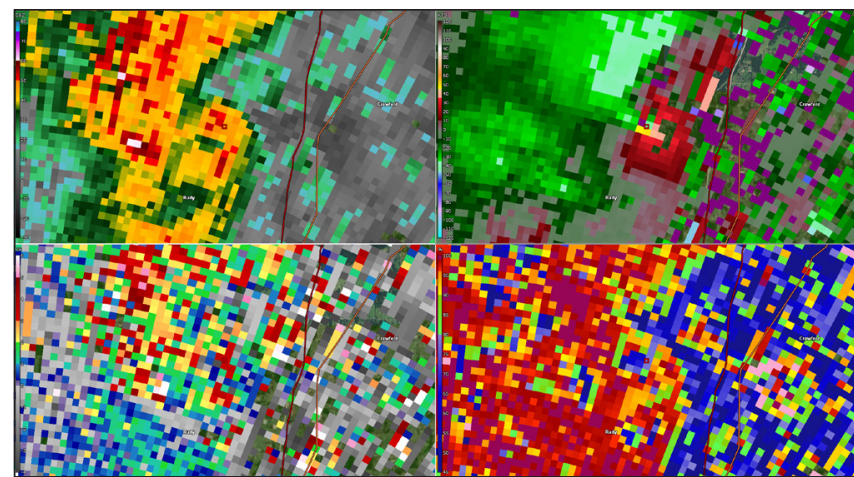

Figure 2. Data from the Fort Smith, AR, WSR-88D (KSRX) showing a supercell storm containing a velocity couplet with large Vrot values and a tornadic debris signature. Top left is base reflectivity; top right is storm-relative radial velocity; bottom left is spectrum width; and bottom right is correlation coefficient. These data pass quality control checks and are located very near the start of the EF2 damage associated with the Crawford County tornado.

of diameters larger than $9.26 \mathrm{~km}(5 \mathrm{n} \mathrm{mi})$. The data were then quality controlled subjectively for aliasing errors, range folding, vertical sidelobe contamination, or areas of reflectivity $<20 \mathrm{dBZ}$ - in a similar fashion to S15, T17, and G16 based on Doviak and Zrnić (2006), Piltz and Burgess (2009), and WDTD (2018e). Figure 3 shows an example of rejected velocity data (outlined in yellow) that appears to be due to vertical side lobe contamination. The weaker mesocyclone with reliable velocity data was used for this slice. The data were analyzed using GR2Analyst versions 2.13 and 2.73.

\section{b. Data gathered and analyzed}

The procedure described above partitioned the 290 cases as follows:

- 85 significant tornado supercell cases,

- 85 NIL supercell cases (45 nontornadic severe, $22 \mathrm{EF} 0$, and $18 \mathrm{EF} 1$ ),

- 60 significant tornado QLCS cases, and

- 60 NIL QLCS cases (37 nontornadic severe, 12 EF0, and 11 EF1).

The cases were selected from 2015 to 2018, and the radars for all cases had the Supplemental Adaptive Intra-Volume Low-Level Scan (SAILS, www.weather. gov/gsp/sails) upgrade in place, which increased the number of $0.5^{\circ}$ elevation scans embedded within a VS 


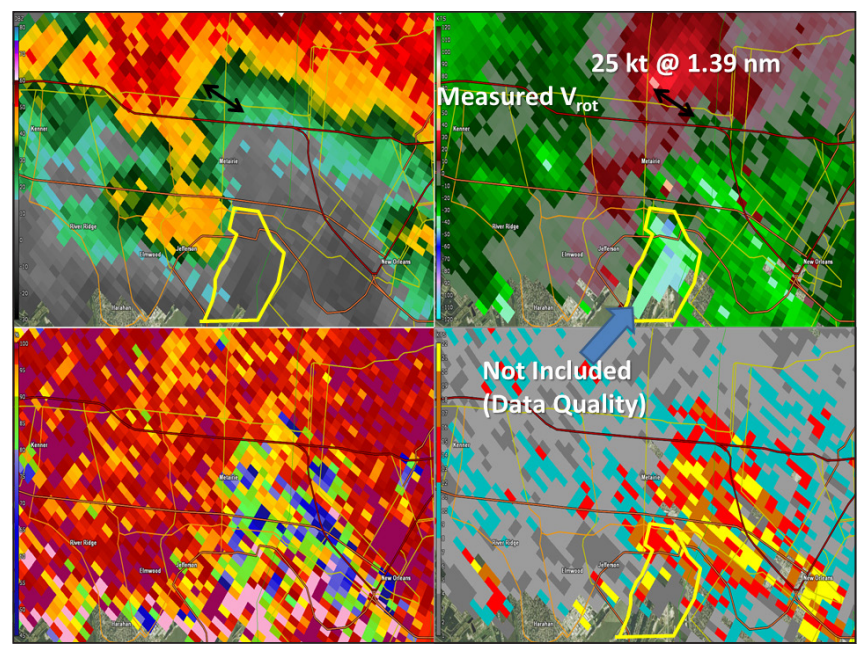

Figure 3. Radar base reflectivity (top left), stormrelative radial velocity (top right), correlation coefficient (bottom left), and spectrum width (bottom right) in an illustration of the method used to gather $V_{\text {rot }}$ with an example of vertical sidelobe contamination or some other data quality issue (outlined in yellow) that prevented the stronger inbounds from being used to calculate rotational speed. The black arrows on the top two panels represent the location of the $V_{\max }$ and $V_{\min }$ pixels used to calculate the $V_{\text {rot }}$.

to two. SAILS was active for 280 of the possible 290 cases. The Multiple Elevation Scan Options for SAILS (MESO-SAILS) feature became available during the data collection window for the study, which allows the radar operator to select between 1 and 3 additional $0.5^{\circ}$ elevation scans (for a maximum of four per VS). However, for consistency only one additional $0.5^{\circ}$ elevation scan was used per VS because a majority of selected cases predated the advent of MESO-SAILS or were executed in SAILS-1 mode, which only provides one supplemental $0.5^{\circ}$ elevation scan (www.roc.noaa. gov/WSR88D/PublicDocs/NewTechnology/MESOSAILS_Description_Briefing_Jan_2014.pdf).

The following base data were then collected for each case:

- maximum $V_{\text {rot }}$ of the VS and height above radar level (ARL) at which the highest RSC was detected,

- distance between the center of the $V_{\max }$ and $V_{\min }$ pixels (mesocyclone width),

- depth of a mesocyclone containing a $V_{\text {rot }}$ of $\geq 15.43 \mathrm{~m} \mathrm{~s}^{-1}$ (30 kt) (per G16),

- peak, near-gate-to-gate $\Delta \mathrm{V}\left(V_{\max }-V_{\min }\right)$ in the lowest scan, within one range bin (per G16),
- storm mode,

- azimuth and range from the detecting WSR$88 \mathrm{D}$,

- whether a tornado was occurring 5, 10, 15,20 and $25 \mathrm{~min}$ in the future and the rating of any corresponding surveyed damage, and

- maximum $V_{\text {rot }}$ and diameter of any couplets detected on the $0.5^{\circ}$ slice (including SAILS).

A mesocyclone strength with $V_{\text {rot }} \geq 15.43 \mathrm{~m} \mathrm{~s}^{-1}$ (30 $\mathrm{kt})$ was chosen as it is close to the threshold between minimal and moderate mesocyclone defined by Andra (1997) and because of the threshold's effectiveness in the G16 study. These data were collected at the onset of the case as well as for the previous four VSs (including SAILS). The selection of four preceding VSs was based on skill scores from G16 that showed predictability deteriorates significantly in data more than four VSs in advance of significant tornado development.

\section{c. Combined parameters}

Multiple items then were manually evaluated from the base data, including:

- the change in base data value from one VS to the next, and the average change between these data in varying series of VSs, and

- the presence of the following:

- $V_{\text {rot }}$ that was $\geq 25.72 \mathrm{~m} \mathrm{~s}^{-1}(50 \mathrm{kt})$ in any of the three prior VSs (hereafter 50VROT15, per G16),

- $V_{\text {rot }}$ that was $\geq 20.57 \mathrm{~m} \mathrm{~s}^{-1}$ (40 kt) that persisted during the prior three VSs (hereafter P40VROT, per G16),

- a mesocyclone $\geq 2438 \mathrm{~m}(8000 \mathrm{ft})$ in depth with $V_{\text {rot }} \geq 15.43 \mathrm{~m} \mathrm{~s}^{-1}(30 \mathrm{kt})$ at each elevation angle, persisting for $\geq 2 \mathrm{VSs}$ (hereafter PMESO30, per G16), and

- $\quad$ near-gate-to-gate $\Delta \mathrm{V} \geq 36.01 \mathrm{~m} \mathrm{~s}^{-1}$ (70 kt) (per G16).

Several combined parameters were calculated from the base data, including:

- RSC (Daintith 2009) calculated as noted previously,

- RSC acceleration (or change) from one VS prior to damage to onset (RCHG5), and an 
average of the onset RSC and RSC for two VSs prior to the onset (RCG10), calculated as:

- $\mathrm{RCHG5}=\mathrm{RSC}_{\text {onset vs }}-\mathrm{RSC}_{\text {one vs prior }}$,

- $\quad \mathrm{RCHG10}=\left[\left(\mathrm{RSC}_{\text {onset vs }}-\mathrm{RSC}_{\text {one vs prior }}\right)+\right.$ $\left(\mathrm{RSC}_{\text {one }}\right.$ vs prior $-\mathrm{RSC}_{\text {two }}$ vs prior $)+$ $\left.\left(\mathrm{RSC}_{\text {two VS prior }}-\mathrm{RSC}_{\text {three VS prior }}\right)\right] / 3$,

- the period of the rotation, calculated as $\mathrm{RPD}=\pi d / V_{\text {rot, }}$ and

- the rotational frequency, calculated as $\mathrm{R}_{\mathrm{f}}=V_{\text {rot }} / \pi d$.

These parameters were further combined in varying weights to evaluate those that were most skillful. These significant tornado predictive parameters (STPPs) were as follows:

- a combination of rotational period (RPD), the height of maximum $V_{\text {rot }}$ (RSC Max Height), and a factor of the depth of the storm mesocyclone, calculated as:

\section{- $\quad S T P P 1=R P D \times R S C$ Max Height $\times 2 /$ 30kt Meso Depth,}

- a combination of rotational frequency $\left(\mathrm{R}_{\mathrm{f}}\right)$ and the depth of the storm mesocyclone, calculated as:

\section{- $\quad S T P P 2=R_{\mathrm{f}} \times 30 \mathrm{kt}$ Meso Depth $/ 1000$,}

- and the rotational speed of the circulation (RSC) combined with the depth of the mesocyclone with a larger influence of the rotational speed, calculated as:

- $\quad S T P P 3=R S C+30 \mathrm{kt}$ Meso Depth $/ 1000$.

The application of these parameters will be discussed in the analysis and discussion section of the paper.

Figure 4 illustrates the full data collection process. The first image is the $0.5^{\circ}$ elevation scan at the onset of the Crawford County, Arkansas, tornado event mentioned previously in the text. Velocity characteristics of this storm were gathered, and because the storm was already exhibiting a mesocyclone with $V_{\text {rot }} \geq 15.43 \mathrm{~m} \mathrm{~s}^{-1}$ (30 kt), the corresponding height was collected as the base of that storm's mesocyclone. The

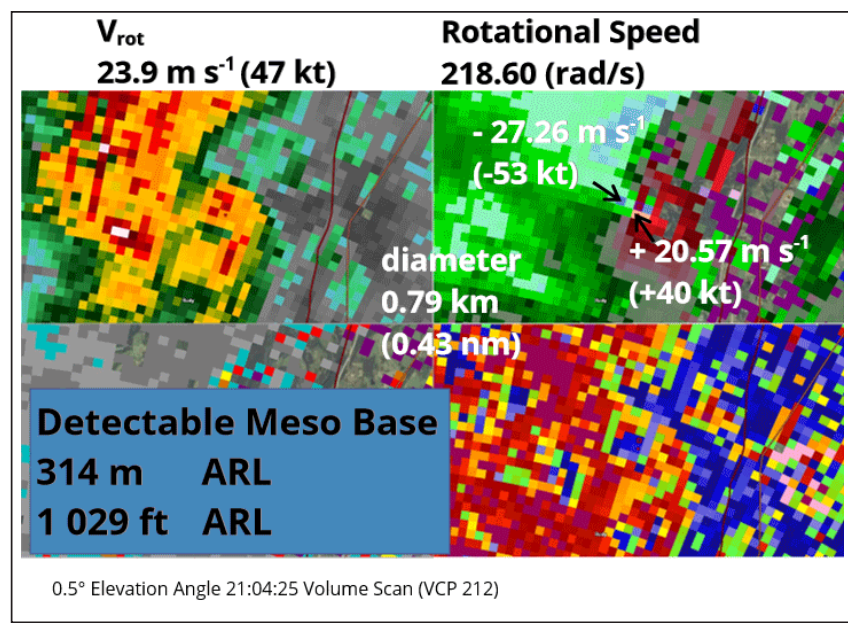

Figure 4. An example of the data gathering process for the study. Radar images are reflectivity (top-left), storm-relative radial velocity (top-right), differential reflectivity (bottom-left), and correlation coefficient (bottom-right). The animation steps forward every 3.5 s. Black arrows indicate the pixels sampled for velocity and diameter information (annotated in white). The top of the image shows the calculated $V_{\text {rot }}$ and rotational speed (in black). The base, top, and total depth of the detectable mesocyclone is provided in a blue box on the bottom left of the image. The maximum rotational speed in this set of data is annotated with a black "MAX" with a red background. Click image for the animation.

peak low-level $\Delta \mathrm{V}$ that was gate-to-gate (or within one range) bin also was collected. The next frame is the $0.9^{\circ}$ elevation angle, which contains the maximum RSC for the VS; therefore, the $V_{\text {rot }}$ and mesocyclone diameter for this level were logged along with the height of the observation (in this case $488 \mathrm{~m}$ or $1600 \mathrm{ft}$ ARL). The next image shows an increased $V_{\text {rot }}$, but the increase in diameter between the two maximum pixels decreased the RSC from the values observed in the previous slice. The next six images show a persistent mesocyclone extending upward through the thunderstorm, with $V_{\text {ro }}$ values remaining $\geq 15.43 \mathrm{~m} \mathrm{~s}^{-1}$ (30 kt) in each slice. The next frame, the $6.4^{\circ}$ slice, is the last to contain a mesocyclone of this strength. This is therefore documented as the top of the mesocyclone. The $7.9^{\circ}$ elevation angle shows a faint mesocyclone, but below the required threshold, so the detected mesocyclone depth for this storm is logged to the nearest $100 \mathrm{ft}$, in this case $3352 \mathrm{~m}(11000 \mathrm{ft})$, with a peak $V_{\text {rot }}$ of 31.15 $\mathrm{m} \mathrm{s}^{-1}(62 \mathrm{kt})$ and diameter at $0.78 \mathrm{~km}(0.43 \mathrm{n} \mathrm{mi})$. For all $0.5^{\circ}$ elevation slices, the $V_{\text {rot }}$ and diameter were collected separately, including for the SAILS data. The 
Table 1. WSR-88D data collected for the indicated full VSs for the example case given. All data for this study were collected in a similar format. Note that $1 \mathrm{kt}=0.5144 \mathrm{~m} \mathrm{~s}-1,1 \mathrm{n} \mathrm{mi}=1.85 \mathrm{~km}$, and $1 \mathrm{ft}=0.3048 \mathrm{~m}$.

\begin{tabular}{|c|c|c|c|c|c|c|}
\hline \multicolumn{7}{|c|}{$\begin{array}{l}\text { Velocity data for the Crawford County, AR, tornado as collected from the KSRX WSR-88D } \\
\text { tornado was at } 017^{\circ} \text { at } 16 \mathrm{~nm} \text { distance at onset of EF2 damage }\end{array}$} \\
\hline & Time & $\begin{array}{c}V_{\text {rot }} \\
\text { maximum } \\
(\mathrm{kt})\end{array}$ & $\begin{array}{l}\text { Diameter } \\
\text { (n mi) }\end{array}$ & $\begin{array}{c}\text { Rotational } \\
\text { speed } \\
\left(\operatorname{rad~s}^{-1}\right)\end{array}$ & $\begin{array}{l}\text { Mesocyclone } \\
\text { depth } \\
\text { (ft) }\end{array}$ & $\begin{array}{c}0.5^{\circ} \Delta V \\
\text { (kt) }\end{array}$ \\
\hline $\begin{array}{l}\text { Onset } \\
\text { VS }\end{array}$ & 2104 & 61 & 0.43 & 80.90 & 10900 & 90 \\
\hline $\begin{array}{l}\text { One VS } \\
\text { prior }\end{array}$ & 2058 & 54 & 3.33 & 37.27 & 12000 & 30 \\
\hline $\begin{array}{l}\text { Two VS } \\
\text { prior }\end{array}$ & 2051 & 59 & 2.92 & 40.41 & 14100 & 55 \\
\hline $\begin{array}{l}\text { Three } \\
\text { VS prior }\end{array}$ & 2044 & 56 & 1.27 & 88.18 & 8200 & 40 \\
\hline $\begin{array}{l}\text { Four } \\
\text { VS prior }\end{array}$ & 2039 & 55 & 2.67 & 41.19 & 10000 & 35 \\
\hline
\end{tabular}

Table 2. WSR-88D data collected from the $0.5^{\circ}$ elevation angle, which included 1 SAILS per VS, for the example case.

\begin{tabular}{|c|c|c|c|c|}
\hline \multicolumn{4}{|c|}{$\begin{array}{c}\text { Velocity data for the Crawford County, AR, tornado as collected from the KSRX WSR-88D using only } \\
\text { data from the } \mathbf{0 . 5 ^ { \circ }} \text { elevation angles, including SAILS }\end{array}$} \\
\hline & Time & $\mathbf{0 . 5}^{\mathbf{0}} \boldsymbol{V}_{\text {rot }}$ (kt) & Diameter (n mi) & $\begin{array}{c}\text { Rotational speed } \\
\text { (rad s }\end{array}$ \\
\hline Damage onset & 2104 & 47 & 0.43 & 218.60 \\
\hline 1 scan prior & 2102 & 55 & 0.97 & 113.40 \\
\hline 2 scans prior & 2057 & 38 & 0.34 & 223.52 \\
\hline 3 scans prior & 2051 & 32 & 1.58 & 40.50 \\
\hline 4 scans prior & 2049 & 26 & 1.67 & 31.13 \\
\hline 5 scans prior & 2045 & Data Quality Issues & & \\
\hline 6 scans prior & 2043 & 27 & 3.32 & 16.26 \\
\hline 7 scans prior & 2038 & 26 & 2.94 & 17.68 \\
\hline
\end{tabular}

base data for each event were collected as shown in Table 1 , with $0.5^{\circ}$ elevation data as shown in Table 2.

Data that only contained one slice with a mesocyclone of the requisite strength were assigned an arbitrary depth of $304.8 \mathrm{~m}$ (1000 ft); no extrapolation to ground level was made. Thus, a detected mesocyclone with the $0.5^{\circ}$ elevation angle at $1524 \mathrm{~m}(5000 \mathrm{ft})$ extending to $3048 \mathrm{~m}(10000 \mathrm{ft})$ would be counted as a depth of $1524 \mathrm{~m}(5000 \mathrm{ft})$, even if a tornado was occurring and it was likely that the mesocyclone extended further to the ground. This adheres to the idea of capturing what the forecaster can detect with confidence using the WSR-88D, rather than the exact physical processes that are occurring.

The fact that any portion of a mesocyclone below the $0.5^{\circ}$ beam height is not observed raises the question of whether the data are biased (e.g., deeper mesocyclones being detected at closer range to the radar). It was evaluated whether this would introduce a significant bias to the data, with mesocyclones closer to the radar producing deeper values. Figure 5 shows a plot of supercell cases in the present study. The correlation coefficient for these data is 0.11 , with a slight tendency for deeper mesocyclones to be detected at longer range. This hints at the idea of stronger and deeper mesocyclones being detected more readily at 


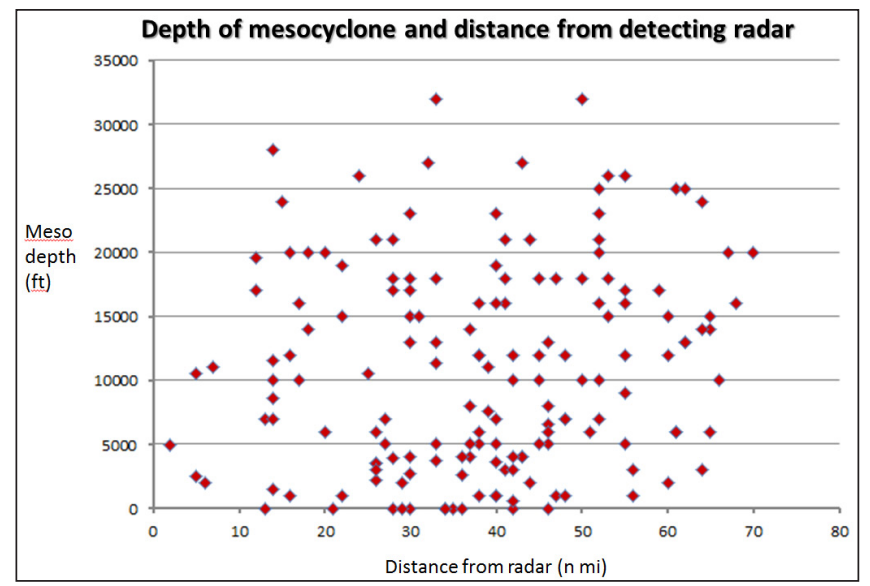

Figure 5. Scatter plot of 170 supercell cases showing the relationship of the depth of the mesocyclone $(1 \mathrm{ft}$ $=0.3048 \mathrm{~m}$ ) versus the distance of the mesocyclone $(1 \mathrm{n} \mathrm{mi}=1.852 \mathrm{~km})$ from the radar. The correlation coefficient between the two is 0.11 .

such distances, but the correlation is too small to be meaningful.

\section{d. Statistical tests and skill evaluation}

Once the data were gathered, they were organized into tables separated by whether they were associated with a significant tornado event. Means, standard deviations, quartiles, and medians were identified to initially examine for thresholds of significance. Values were then tested at each VS of the process. Table 3 shows an abbreviated table for simple $V_{\text {rot }}$ values, with cases 7 through 85 omitted. Cases were examined for varying thresholds of significance, such as 20.6, 25.7, or $30.9 \mathrm{~m} \mathrm{~s}^{-1}(40,50$, or $60 \mathrm{kt}) V_{\text {rot }}$ at maximum RSC. Prospective significant thresholds were then used to collect cases into a contingency table (Table 4) and Pearson's $\chi^{2}$ test for independence (Rao 2002) was conducted to evaluate for statistical significance. This allowed for rapid testing of multiple thresholds across multiple VSs. A p value for statistical independence of $p<0.05$ was selected as an initial threshold for evaluation, with values of $\mathrm{p}<0.01$ preferred. Thresholds passing these tests then were evaluated for usefulness in predicting significant tornado development using the probability of detection (POD), false alarm ratio (FAR), critical success index (CSI, Schaefer 1990), and Heidke Skill score (HSS, Heidke 1926) metrics. The thresholds of significance that scored highest then were documented for each parameter at each VS iteration. In the $V_{\text {rot }}$ at maximum RSC example given in Table
2 the threshold did not change with time (e.g., across any of the preceding VSs), but many of the thresholds of significance for other parameters were adjusted with time to the threshold that showed the strongest skill for that iteration.

For each significant tornado case, the presence or absence of a warning was recorded. If a warning was in effect, the warning's lead time to the onset of EF2+ damage and the wording/tag used at the onset of damage (e.g., radar indicated, spotter confirmed, considerable, or catastrophic) also was recorded from the initial warning and subsequent severe weather statements.

\section{Analysis and discussion}

\section{a. $\quad$ Warning status for selected events}

The warning status for the 145 significant tornado events is summarized in Table 5. POD and lead time statistics were reasonably close to the 3 -yr NWS average from June 2015 to June 2018 (verification.nws.noaa. gov), which show a significant tornado POD of 0.737 and an initial lead time of $16.2 \mathrm{~min}$. The stark difference in skill between supercell and QLCS significant tornado events is noteworthy. Also interesting is the relatively strong skill at having a warning in effect for significant tornado events, although note this is likely positively biased as only cases within $129.6 \mathrm{~km}(70 \mathrm{n} \mathrm{mi})$ of a WSR-88D met the criteria for the study, making these events easier to detect with confidence. This snapshot, however, does show a need for higher confidence methods to identify significant tornadoes with improved lead time. It also suggests room for improvement in providing adequate warning for significant $(\mathrm{EF} 2+)$ QLCS events - the difficulty of which has been previously documented (Trapp et al. 1999; Brotzge et al. 2013).

Few events had enhanced (considerable or catastrophic tag) wording in place at the onset of significant damage, and slightly more events had confirmed the presence of a tornado prior to the onset of significant damage via either radar or visual confirmation. Twenty-seven events had "confirmed tornado" wording included within 5 min of the onset of significant damage. However, about $80 \%$ of the warned significant tornado events had the default "radar indicated rotation" as the basis statement at the onset of significant tornado damage, pointing to the challenge in confirming a tornado either visually or via radar prior to the onset of significant damage. Ninety-one percent of 
Table 3. Abbreviated example of how each tested parameter was evaluated for thresholds of significance. For simplicity in this example raw data from only 6 cases are shown, but 85 cases of each condition were evaluated. This method was used for each collected and derived parameter to quickly identify potential thresholds of significance.

\begin{tabular}{|c|c|c|c|c|c|c|c|c|}
\hline \multicolumn{7}{|c|}{$V_{r o t}$ at maximum RSC data for significant supercell tornado cases (kt) } & \multirow{2}{*}{$\begin{array}{c}\text { Threshold } \\
\text { Testing }\end{array}$} & \multirow{2}{*}{$\begin{array}{c}\text { Cases } \\
\text { above } \\
\text { threshold }\end{array}$} \\
\hline & Case 1 & Case 2 & Case 3 & Case 4 & Case 5 & Case 6... & & \\
\hline Onset VS & 50 & 58 & 62 & 52 & 72 & 52 & $\begin{array}{l}\# \text { cases } \\
\geq 50 \mathrm{kt}\end{array}$ & $63 / 85$ \\
\hline $\begin{array}{c}\text { One } \\
\text { VS prior }\end{array}$ & 50 & 40 & 54 & 55 & 64 & 94 & $\begin{array}{l}\# \text { cases } \\
\geq 50 \mathrm{kt}\end{array}$ & $53 / 85$ \\
\hline $\begin{array}{c}\text { Two } \\
\text { VS prior }\end{array}$ & 60 & 40 & 59 & 48 & 59 & 46 & $\begin{array}{l}\# \text { cases } \\
\geq 50 \mathrm{kt}\end{array}$ & $43 / 85$ \\
\hline $\begin{array}{l}\text { Three } \\
\text { VS prior }\end{array}$ & 43 & 31 & 56 & 61 & 67 & 56 & $\begin{array}{l}\# \text { cases } \\
\geq 50 \mathrm{kt}\end{array}$ & $35 / 85$ \\
\hline $\begin{array}{c}\text { Four } \\
\text { VS prior }\end{array}$ & 35 & 30 & 55 & 46 & 57 & 50 & $\begin{array}{l}\text { \# cases } \\
\geq 50 \mathrm{kt}\end{array}$ & $26 / 85$ \\
\hline \multicolumn{9}{|c|}{$V_{r o t}$ at maximum RSC data for NIL supercell cases $(\mathrm{kt})$} \\
\hline & Case 1 & Case 2 & Case 3 & Case 4 & Case 5 & Case $6 . .$. & & \\
\hline Onset VS & 40 & 40 & 40 & 53 & 65 & 50 & $\begin{array}{l}\text { \# cases } \\
\geq 50 \mathrm{kt}\end{array}$ & $18 / 85$ \\
\hline $\begin{array}{c}\text { One } \\
\text { VS prior }\end{array}$ & 33 & 46 & 46 & 58 & 62 & 59 & $\begin{array}{l}\text { \# cases } \\
\geq 50 \mathrm{kt}\end{array}$ & $20 / 85$ \\
\hline $\begin{array}{c}\text { Two } \\
\text { VS prior }\end{array}$ & 27 & 45 & 45 & 52 & 45 & 54 & $\begin{array}{l}\# \text { cases } \\
\geq 50 \mathrm{kt}\end{array}$ & $18 / 85$ \\
\hline $\begin{array}{l}\text { Three } \\
\text { VS prior }\end{array}$ & 33 & 43 & 41 & 54 & 48 & 58 & $\begin{array}{l}\text { \# cases } \\
\geq 50 \mathrm{kt}\end{array}$ & $14 / 85$ \\
\hline $\begin{array}{c}\text { Four } \\
\text { VS prior }\end{array}$ & 37 & 46 & 38 & 50 & 46 & 55 & $\begin{array}{l}\# \text { cases } \\
\geq 50 \mathrm{kt}\end{array}$ & $15 / 85$ \\
\hline
\end{tabular}

warnings contained default protective action language and not the enhanced wording designed specifically for a significant tornado. This analysis factors in initial warnings and follow-up severe weather statements. This presents a potentially important consideration for storm messaging and is a primary motivator in attempting to find documented precursor signals for significant tornado events in order to potentially increase the number of events where this enhanced wording can be applied accurately in advance.

\section{b. Initial evaluation}

The data were initially examined for factors that differentiated significant from NIL events, using all events, regardless of storm mode. These results were unclear. For example, variables used in G16, such as
50VROT15 and P40VROT, correctly differentiated between significant and NIL cases only for 142 and 150 cases, respectively, out of 290 . However, when the events were separated by storm mode, useful results began to emerge. A number of statistically significant and skillful precursors were identified for supercell events, with virtually all showing little to no skill with QLCS events.

c. Precursor signals for significant supercell tornado events

\section{1) ROTATIONAL VELOCITY AT THE POINT OF MAXIMUM ROTATIONAL SPEED}

A number of the parameters collected and tested showed statistical significance for differentiating, with lead 
Table 4. Contingency table of data from Table 3 used to evaluate POD/FAR/CSI/HSS skill scores and conduct Pearson's $\chi^{2}$ for independence. This method was repeated with all variables tested.

\begin{tabular}{|l|c|c|}
\hline \multicolumn{2}{|c|}{$V_{\text {rot }}$ at maximum RSC discriminating between significant tornado and NIL cases } \\
\hline Significant tornado events & $\mathbf{2 0}$ & $<\mathbf{5 0}$ \\
\hline NIL cases & 63 & 22 \\
\hline \multicolumn{2}{|c|}{18} & 67 \\
\hline
\end{tabular}

Table 5. The warning status for the significant tornado events selected for the study separated by storm mode, and combined together. Percentages of the events meeting the given criteria are included in parenthesis for convenience. Warning/Statement information obtained from Iowa Environmental Mesonet (mesonet.agron.iastate.edu/cow/).

\begin{tabular}{|l|c|c|c|}
\hline & Supercell & QLCS & Total \\
\hline Warned & $77 / 85(0.905)$ & $35 / 60(0.583)$ & $107 / 145(0.737)$ \\
\hline Confirmed at onset & $21 / 85(0.247)$ & $6 / 60(0.100)$ & $27 / 145(0.186)$ \\
\hline $\begin{array}{l}\text { Enhanced wording } \\
\text { at onset }\end{array}$ & $12 / 85(0.141)$ & $2 / 60(0.033)$ & $14 / 145(0.096)$ \\
\hline $\begin{array}{l}\text { Average lead time to } \\
\text { significant damage }\end{array}$ & $17.64 \mathrm{~min}$ & $13.14 \mathrm{~min}$ & $16.21 \mathrm{~min}$ \\
\hline
\end{tabular}

time, between significant tornado and weak/nontornadic events in supercell storm modes. For example, $V_{\text {rot }}$ $\geq 25.72 \mathrm{~m} \mathrm{~s}^{-1}(50 \mathrm{kt}$ ) (Table 6) - taken from the point in the VS showing the highest RSC-showed some skill at up to two VSs prior to the onset of damage. As mentioned earlier, many of the NIL events for this study were specifically selected from the S15 and T17 database for their high $V_{\text {rot }}$ values to examine what other defining characteristics might exist. As a result, cases of high $V_{\text {rot }}$ are presumably overrepresented in this database compared to their real-world distribution. Use of maximum $V_{\text {rot }}$ values also held up well when retesting parameters identified in G16 (Table 7). The 50VROT15 parameter appeared to show the strongest skill in identifying significant tornado events out of this subset, whereas P40VROT scored more poorly, but still showed consistency, as did 70LLDV, and PMESO30. These values were fairly close to the results found in G16.

This seems to validate existing guidance provided by the NWS WDTD that uses a so-called "30-40-50" rule for first guess IBW decision making (WDTD 2018b). This training emphasizes peak skill scores from S15, T17, G16, and Kingfield and LaDue (2015), indicating that $V_{\text {rot }} \geq 25.72 \mathrm{~m} \mathrm{~s}^{-1}(50 \mathrm{kt})$ is a threshold that should be concerning for the potential existence or imminent threat of a significant supercell tornado, regardless of other cues. Note that this is the $V_{\text {rot }}$ at peak RSC anywhere in the storm (excluding storm top divergence signals, which were not considered part of the mesocyclone; WDTD 2018a), and not just the lowest available elevation angle.

\section{2) MESOCYCLONE DEPTH}

The presence of a mesocyclone with $V_{\text {rot }} \geq 15.4 \mathrm{~m}$

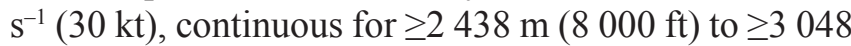
$\mathrm{m}(10000 \mathrm{ft})$, also was a somewhat skillful determinant out to four VSs in advance of significant damage (Table 8). Finding the optimal mesocyclone depth was challenging, with a fairly broad peak in skill between values of $2438 \mathrm{~m}(8000 \mathrm{ft})$ and $3048 \mathrm{~m}(10000 \mathrm{ft})$, which can be inferred by the variability in skill scores shown in the table. This variability is a result of the tested mesocyclone depth of significance being increased as one moves further back in time from the onset of the event. This is similar to the PMESO30 parameter, but looked at the mesocyclone instantaneously rather than whether the feature persisted for two or more VSs.

\section{3) ROTATIONAL SPEED AND ACCELERATION}

RSC showed a degree of skill out to two VSs (Table 9). As with some of the other metrics, the significance 
Table 6. Skill scores for using peak volumetric $V_{r o t} \geq 25.72 \mathrm{~m} \mathrm{~s}^{-1}(50 \mathrm{kt})$ at the point of maximum rotational speed if used to provide warning of significant tornado events from supercell storm modes. $\chi^{2} \geq 9.210$ rejects the null hypothesis of theoretical distribution at $p \geq 0.01$. Each iteration contained 170 supercell cases.

\begin{tabular}{|l|c|c|c|c|c|}
\hline \multicolumn{5}{|c|}{ Maximum volumetric $\left.\boldsymbol{V}_{\text {rot }} \geq \mathbf{2 5 . 7 2} \mathbf{~ m ~ s}^{\mathbf{- 1}} \mathbf{( 5 0} \mathbf{~ k t}\right)$ to identify significant tornado events } \\
\hline & POD & FAR & CSI & HSS & $\boldsymbol{\chi}^{\mathbf{2}}$ \\
\hline Onset & 0.778 & 0.259 & 0.617 & 0.529 & 49.19 \\
\hline One VS prior & 0.726 & 0.376 & 0.504 & 0.389 & 31.87 \\
\hline Two VSs prior & 0.704 & 0.489 & 0.421 & 0.301 & 37.31 \\
\hline Three VSs prior & 0.714 & 0.583 & 0.357 & 0.252 & 14.27 \\
\hline Four VSs prior & 0.634 & 0.682 & 0.268 & 0.139 & 5.76 \\
\hline
\end{tabular}

Table 7. Skill scores for tests conducted in this study's dataset from variables found to be skillful in G16.

\begin{tabular}{|c|c|c|c|c|}
\hline & 50VROT15 & P40VROT & PMESO30 & 70LLDV \\
\hline POD & 0.742 & 0.667 & 0.649 & 0.779 \\
\hline FAR & 0.142 & 0.214 & 0.305 & 0.369 \\
\hline CSI & 0.660 & 0.559 & 0.504 & 0.535 \\
\hline HSS & 0.562 & 0.385 & 0.314 & 0.452 \\
\hline$\chi^{2}$ & 53.34 & 28.96 & 23.47 & 45.59 \\
\hline
\end{tabular}

Table 8. Same as Table 6, but for the depth of a detectable mesocyclone with $V_{\text {rot }} \geq 15.4 \mathrm{~m} \mathrm{~s}^{-1}$ (30 kt) for the given height and time relative to the onset of EF2+ damage.

\begin{tabular}{|c|c|c|c|c|c|}
\hline \multicolumn{6}{|c|}{ Mesocyclone depth $\geq 15.4 \mathrm{~m} \mathrm{~s}^{-1}(30 \mathrm{kt})$} \\
\hline & POD & FAR & CSI & HSS & $\chi^{2}$ \\
\hline $\begin{array}{l}\geq 2438 \mathrm{~m} \\
(8000 \mathrm{ft}) \\
\text { at onset }\end{array}$ & 0.636 & 0.258 & 0.520 & 0.317 & 20.95 \\
\hline $\begin{array}{l}\geq 3048 \mathrm{~m} \\
(10000 \mathrm{ft}) \\
\text { one VS prior }\end{array}$ & 0.602 & 0.305 & 0.475 & 0.235 & 13.41 \\
\hline $\begin{array}{l}\geq 3048 \mathrm{~m} \\
(10000 \mathrm{ft}) \\
\text { two VS prior }\end{array}$ & 0.647 & 0.352 & 0.478 & 0.234 & 14.70 \\
\hline $\begin{array}{l}\geq 3048 \mathrm{~m} \\
\text { (10 000 ft) } \\
\text { three VS prior }\end{array}$ & 0.667 & 0.388 & 0.468 & 0.273 & 18.06 \\
\hline $\begin{array}{l}\geq 3048 \mathrm{~m} \\
(10000 \mathrm{ft}) \\
\text { four VS prior }\end{array}$ & 0.716 & 0.376 & 0.500 & 0.376 & 29.34 \\
\hline
\end{tabular}

threshold for RSC is adjusted in time, from a high of 40 $\mathrm{rad} \mathrm{s}^{-1}$ at the onset of damage to a low of $25 \mathrm{rad} \mathrm{s}^{-1}$ at the second or third VS prior to onset.

Both RCHG5 and RCHG10 showed skill as a diagnostic tool (Table 10). The threshold of significance was identified as $5 \mathrm{~Hz}$. RCHG5 showed stronger skill, producing a particularly low FAR as one of the more skillful discriminators identified. Thus, a marked increase in rotational speed above the significant threshold from one VS to another serves as a skillful 
Table 9. Same as Table 6, but for the peak rotational speed (RSC) detected within the storm at the times given.

\begin{tabular}{|c|c|c|c|c|c|}
\hline \multicolumn{5}{|c|}{ Rotational Speed at given periods relative to the onset of significant tornado damage (RSC) $\left(\mathbf{r a d ~ s}^{\mathbf{- 1}}\right)$} \\
\hline & POD & FAR & CSI & HSS & $\chi^{\mathbf{2}}$ \\
\hline 40 at onset & 0.728 & 0.159 & 0.642 & 0.529 & 48.44 \\
\hline $\mathbf{3 5}$ one VS prior & 0.667 & 0.285 & 0.526 & 0.361 & 22.17 \\
\hline $\mathbf{2 5}$ two VS prior & 0.605 & 0.188 & 0.530 & 0.282 & 32.31 \\
\hline $\begin{array}{c}\text { 25 three } \\
\text { VS prior }\end{array}$ & 0.586 & 0.265 & 0.484 & 0.182 & 18.77 \\
\hline
\end{tabular}

Table 10. Same as Table 6, but for the average change in RSC at the given periods, using $5 \mathrm{~Hz}$ as the threshold of significance.

\begin{tabular}{|c|c|c|c|c|c|}
\hline \multicolumn{5}{|c|}{ Average change in RSC at given periods relative to the onset of significant tornado damage } \\
\hline & POD & FAR & CSI & HSS & $\chi^{2}$ \\
\hline RCHG10 & 0.838 & 0.261 & 0.645 & 0.597 & 67.00 \\
\hline RCHG5 & 0.826 & 0.321 & 0.593 & 0.537 & 60.35 \\
\hline
\end{tabular}

indicator of whether a supercell is about to produce a significant tornado. As an example of the significance threshold for rotational acceleration, a $7.7 \mathrm{~m} \mathrm{~s}^{-1}(15$ kt) increase in $V_{\text {rot }}$ with a $3.7 \mathrm{~km}(2 \mathrm{n} \mathrm{mi})$ decrease in mesocyclone width would exceed $5 \mathrm{~Hz}$, while a $2.5 \mathrm{~m} \mathrm{~s}^{-1}$ $(5 \mathrm{kt})$ increase in $V_{\text {rot }}$ with a $3.7 \mathrm{~km}(2 \mathrm{n} \mathrm{mi})$ decrease in mesocyclone width would not. Rotational acceleration from one VS prior to two VSs prior to the onset of damage approached, but did not meet, thresholds for statistical significance.

Rotational period and rotational frequency also were calculated and the results of those tests are presented in the appendix of this paper.

\section{4) COMBINED PARAMETERS}

More consistent skill, which persisted at substantial lead times, was present when the parameters were combined. Relaxing the threshold of significance for earlier VSs allowed for statistical significance at up to four VSs in advance of the onset of EF2+ damage for STPP1, STPP2, and STPP3. Notably, skill also was relatively high when averaging the onset and two prior VSs of STPP2. Tables 11-13 shows skill scores for these parameters. Table 14 shows skill scores for an average of the parameters from one VS before the onset of damage to three VSs before.

Figures $6 \mathrm{a}$ and $6 \mathrm{~b}$ visualize the CSI scores for individual and combined parameters from the onset of significant damage out to four VSs prior. Values are removed once tests for statistical significance fall below $p=0.05$. The nuances of POD and FAR with each parameter can be examined in the preceding tables, but the overall durability of skill in the STPP 1-3 parameters, when contrasted with individual elements, is clear. Combining other parameters (e.g., RSC and height of maximum RSC) for a "tightening and descending" signal was tested but did not show significant results beyond the onset VS.

The results suggest (as one might anticipate) that storms with deeper mesocyclones and higher rotational speeds (or lower rotational periods as is the case with STPP1) tend to be the supercells that produce significant tornadoes. The proximity of maximum rotational speed to the ground seems to add a very small degree of skill to STPP1, but evaluating the three parameters together suggests that the primary predictive factors are mesocyclone depth and rotational speed/period.

The skill of these combined parameters gives promise to using full volumetric WSR-88D velocity data to forecast significant tornado development with some degree of lead time. Whereas these parameters still do not provide a perfect solution, it follows that combining these data with other documented factors in significant tornado development, such as the mesoscale environment (Thompson et al. 2012), could allow forecasts of sufficient skill for operational use.

Quickly visualizing/evaluating these multi-variable parameters in an operational environment presents a challenge. There are a few methods for this, however, such as providing a detected $\geq 15.43 \mathrm{~m} \mathrm{~s}^{-1}$ (30 kt) mesocyclone depth. It is then possible to produce a 
Table 11. Same as Table 6, but for a combination of RPD, Height of the Maximum RSC and the depth of the mesocyclone using a variable threshold of significance.

\begin{tabular}{|c|c|c|c|c|c|}
\hline \multicolumn{5}{|c|}{$\begin{array}{c}\text { Combining RPD, height of maximum RSC, and a factor of the depth of the mesocyclone to differentiate } \\
\text { between significant tornado and weak/nontornadic events (STPP1) }\end{array}$} \\
\hline & POD & FAR & CSI & HSS & $\chi^{\mathbf{2}}$ \\
\hline \begin{tabular}{c}
$\mathbf{0 . 1 2}$ at onset \\
\hline $\begin{array}{c}\mathbf{0 . 2} \text { one } \\
\text { VS prior }\end{array}$
\end{tabular} & 0.753 & 0.282 & 0.589 & 0.482 & 40.92 \\
\hline $\begin{array}{c}\mathbf{0 . 3} \text { two } \\
\text { VS prior }\end{array}$ & 0.714 & 0.285 & 0.556 & 0.432 & 31.62 \\
\hline $\begin{array}{c}\mathbf{0 . 4} \text { three } \\
\text { VS prior }\end{array}$ & 0.667 & 0.333 & 0.500 & 0.337 & 19.28 \\
\hline $\begin{array}{c}\mathbf{0 . 4} \text { four } \\
\text { VS prior }\end{array}$ & 0.719 & 0.329 & 0.502 & 0.364 & 22.74 \\
\hline
\end{tabular}

Table 12. Same as Table 6, but for the combination of rotational frequency, and the depth of the storm mesocyclone with $V_{\text {rot }} \geq 15.4 \mathrm{~m} \mathrm{~s}^{-1}(30 \mathrm{kt})$.

\begin{tabular}{|c|c|c|c|c|c|}
\hline \multicolumn{5}{|c|}{$\begin{array}{c}\text { Combination of rotational frequency and the depth of the storm mesocyclone differentiating between } \\
\text { significant tornado and weak/nontornadic events (STPP2) }\end{array}$} \\
\hline & POD & FAR & CSI & HSS & $\chi^{2}$ \\
\hline $\mathbf{1 0 0}$ at onset & 0.703 & 0.329 & 0.522 & 0.388 & 26.69 \\
\hline $\mathbf{8 0}$ one VS prior & 0.684 & 0.357 & 0.495 & 0.349 & 22.13 \\
\hline $\mathbf{5 0}$ two VS prior & 0.645 & 0.417 & 0.441 & 0.266 & 14.84 \\
\hline $\begin{array}{c}\mathbf{4 0} \text { three } \\
\text { VS prior }\end{array}$ & 0.667 & 0.341 & 0.495 & 0.341 & 19.88 \\
\hline $\begin{array}{c}\text { 30 four } \\
\text { VS prior }\end{array}$ & 0.651 & 0.293 & 0.513 & 0.338 & 19.30 \\
\hline $\begin{array}{c}\text { Average of 70 at } \\
\text { onset and two } \\
\text { preceding scans }\end{array}$ & 0.701 & 0.170 & 0.612 & 0.486 & 41.03 \\
\hline
\end{tabular}

function of $V_{\text {rot }}$ and mesocyclone width and designate significant values at each threshold.

Figures $7-10$ are nomograms with given mesocyclone depths of $610 \mathrm{~m}(2000 \mathrm{ft}), 2434 \mathrm{~m}$ $(8000 \mathrm{ft}), 4768 \mathrm{~m}(16000 \mathrm{ft})$, and $7620 \mathrm{~m}(25000$ $\mathrm{ft})$ for STPP3. These four values are of no special significance, but do represent a variety of mesocyclone depths from very shallow to quite deep, allowing the user to evaluate the difference that the mesocyclone depth makes in determining which rotational speeds are significant. The green line represents the threshold of significance two to four VSs preceding significant damage. The orange line represents the threshold average during the preceding two VSs, and the red line represents the threshold of significance at the onset of damage. The threshold of significance for the average of the first to third prior VSs is 55; this rests within the yellow zone just above the red line. Highlighting begins in the nomograms at maximum RSC $V_{\text {rot }} \geq 18 \mathrm{~m} \mathrm{~s}^{-1}$ (35 $\mathrm{kt})$ to eliminate instances of false positives with storms with very low $V_{\text {rot }}$ values; this is shown in $\mathrm{S} 15, \mathrm{G} 16$, and $\mathrm{T} 17$ to be less likely to produce significant tornadoes. Storms with RSC and mesocyclone depth thresholds in the yellow shaded region suggest a potential to produce a significant tornado in the near future, while the red regions suggest a more imminent or ongoing threat.

Using spreadsheet programs with preexisting formulas also gives an opportunity to quickly evaluate evolving operational cases quantitatively. Figure 11 shows an example of this task being completed for the 
Table 13. Same as Table 6, but with a larger emphasis on rotational speed than mesocyclone depth.

\begin{tabular}{|c|c|c|c|c|c|}
\hline \multicolumn{6}{|c|}{ The angular speed of the circulation combined with the depth of the mesocyclone with a larger emphasis } \\
on angular speed (STPP3) & HSI & HSS & $\chi^{2}$ \\
\hline $\begin{array}{c}\text { Above 60 } \\
\text { at onset }\end{array}$ & POD & FAR & CSI & 0.529 & 46.87 \\
\hline $\begin{array}{c}\text { Above 50 } \\
\text { one VS prior }\end{array}$ & 0.747 & 0.200 & 0.629 & 0.432 & 31.35 \\
$\begin{array}{c}\text { Above 40 } \\
\text { two VS prior }\end{array}$ & 0.592 & 0.309 & 0.467 & 0.219 & 12.65 \\
$\begin{array}{c}\text { Above 40 } \\
\text { three VS prior }\end{array}$ & 0.617 & 0.292 & 0.492 & 0.222 & 15.66 \\
\hline $\begin{array}{c}\text { Above 30 } \\
\text { four VS prior }\end{array}$ & 0.689 & 0.243 & 0.564 & 0.422 & 29.71 \\
\hline
\end{tabular}

Table 14. Same as Table 6, but using the listed average value of parameters given in the final three VSs preceding the onset of significant damage.

\begin{tabular}{|c|c|c|c|c|c|}
\hline \multicolumn{5}{|c|}{ Parameters when averaging values of the three VSs prior to the onset of EF2 damage } \\
\hline & POD & FAR & CSI & HSS & $\chi^{\mathbf{2}}$ \\
\hline STPP1 of $<\mathbf{0 . 3 5}$ & 0.731 & 0.277 & 0.571 & 0.457 & 35.03 \\
\hline STPP2 of $>\mathbf{5 5}$ & 0.656 & 0.241 & 0.543 & 0.361 & 24.50 \\
\hline STPP3 of $>\mathbf{5 5}$ & 0.650 & 0.358 & 0.477 & 0.296 & 14.34 \\
\hline
\end{tabular}

3 March 2019 Lee County, Alabama, long-track EF4 tornado, with the onset of damage around 2006 UTC marked as the onset VS. Red values indicate values above thresholds for significance, after the user inputs $V_{\text {rot, }}$ mesocyclone diameter, mesocyclone depth, and height of maximum RSC information. Yellow and green values represent values in the 5-15 min threshold and values approaching that threshold, respectively. A version of this spreadsheet, with a second worksheet for user data entry is available online at training.weather. gov/wdtd/resources/stpp-spreadsheet.php.

\section{5) USING ONLY 0.5-DEGREE DATA, INCLUDING SAILS}

Another important piece of information available in the warning environment is the supplemental $0.5^{\circ}$ slice that is part of SAILS produced by the WSR-88D. $V_{\text {rot }}$ and RSC values and their scan-to-scan differences were evaluated for the ability to discriminate between significant and weak/nontornadic events. Multiple parameters applied to these data were evaluated, although slightly fewer overall cases were evaluated owing to data quality issues with the $0.5^{\circ}$ slice and a few cases where SAILS was not active (150 total cases; 75 significant tornado and 75 NIL cases).

The $V_{\text {rot }}$ value showed some skill at discriminating using $23.15 \mathrm{~m} \mathrm{~s}^{-1}$ (45 kt) at onset, and $20.57 \mathrm{~m} \mathrm{~s}^{-1}$ (40 $\mathrm{kt})$ in the prior scan, but the skill plummeted at the second slice, with no statistically significant $V_{\text {rot }}$ values found (Table 15). RSC showed the ability to diagnose significant tornado events at onset, but showed no predictive skill when using only the $0.5^{\circ}$ SAILS data (Table 16). The scan-to-scan differences in values of $\mathrm{RSC}$, one of the most skillful predictors when utilizing the full VS, showed some skill as a diagnostic tool, but barely met $\mathrm{p}<0.05$ thresholds for independence as a predictive tool when averaging from one to three scans prior to the onset of significant tornado damage (Table 17). These data clearly were not as skillful as the full volumetric datasets. This has potential implications for the use of SAILS when analyzing supercell tornadoes, as there appears to be good diagnostic value in the $0.5^{\circ}$ slice (S15, G16, T17) but little, if any, predictive value. Therefore, when attempting to predict significant supercell tornadoes, time spent on supplementary lower elevation slices may be better spent completing full VSs, until a tornado is in progress. 


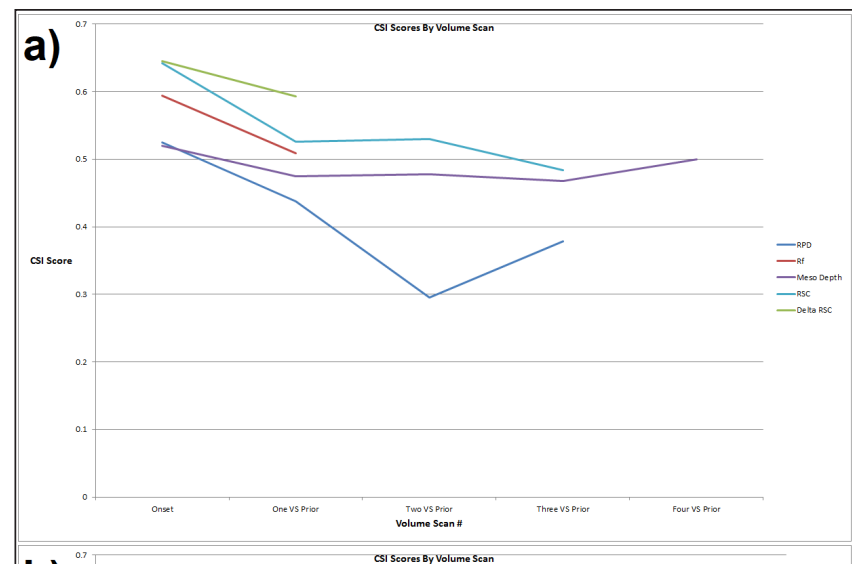

b)

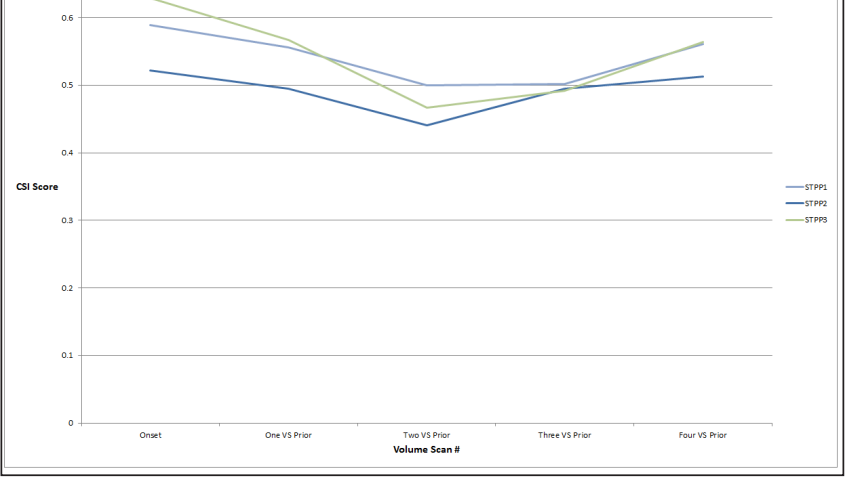

Figure 6. (a) CSI scores plotted for the five listed parameters differentiating between significant and nonsignificant tornado/nontornadic supercell events. Values are plotted from the onset of significant damage to up to four VSs prior to the onset of significant damage. Values that failed tests for statistical significance were dropped from the chart at the time the tests failed. (b) CSI scores for STPP1-3.

Once a tornado begins, SAILS data can be used to provide better real-time estimates of a tornado's location and intensity, but there will still be predictive value in the information presented on higher elevation angles. It also emphasizes the need to focus on the full volumetric dataset in a warning environment and not just the lowest elevations because crucial lead time information may be missed.

\section{6) EXAMINING FOR DAMAGE LONGEVITY}

In an attempt to quantify when significant damage might occur for a longer period of time, all of the above parameters also were evaluated against significant tornadoes that persisted for more than one VS. The STPP3 parameter showed the best skill at discriminating between these events when the threshold

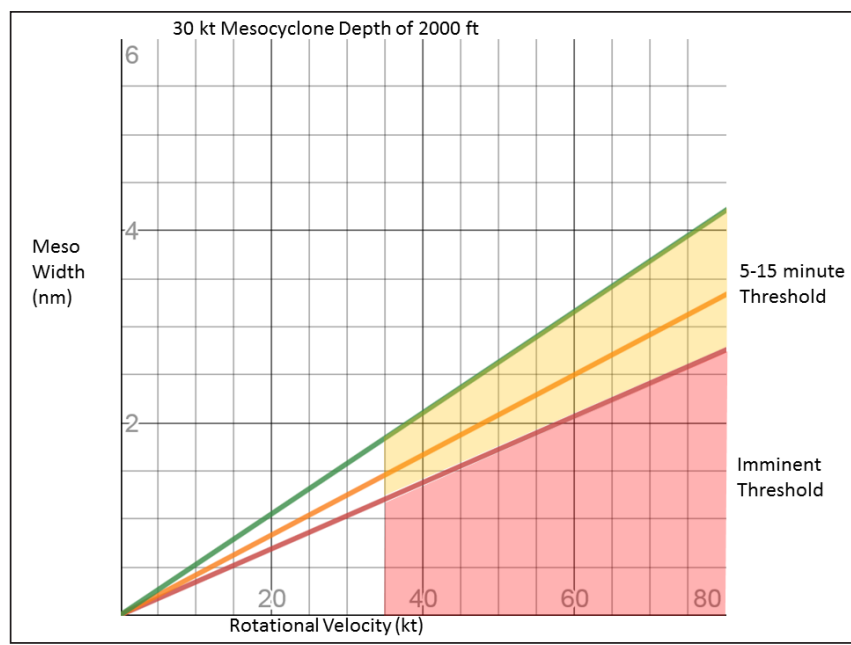

Figure 7. Plots of STPP3 given a $15.43 \mathrm{~m} \mathrm{~s}^{-1}(30 \mathrm{kt})$ mesocyclone with a depth of $607 \mathrm{~m}(2000 \mathrm{ft})$. In this form, $V_{\text {rot }}\left(\mathrm{x}\right.$ axis; $\left.1 \mathrm{kt}=0.5144 \mathrm{~m} \mathrm{~s}^{-1}\right)$ and the width of the mesocyclone (y axis; $1 \mathrm{n} \mathrm{mi}=1.852 \mathrm{~km}$ ) can be plotted to determine significant tornado potential. The green line represents the threshold of significance for a significant tornado from two to four VSs into the future; the orange line is an average of the preceding two VSs; and the red line is the threshold for a significant tornado in progress. The yellow shaded area represents a $V_{\text {rot }} /$ mesocyclone width value significant at 5-15 min lead time for significant tornado potential, where the red shaded area represents significance for an imminent/ ongoing significant tornado.

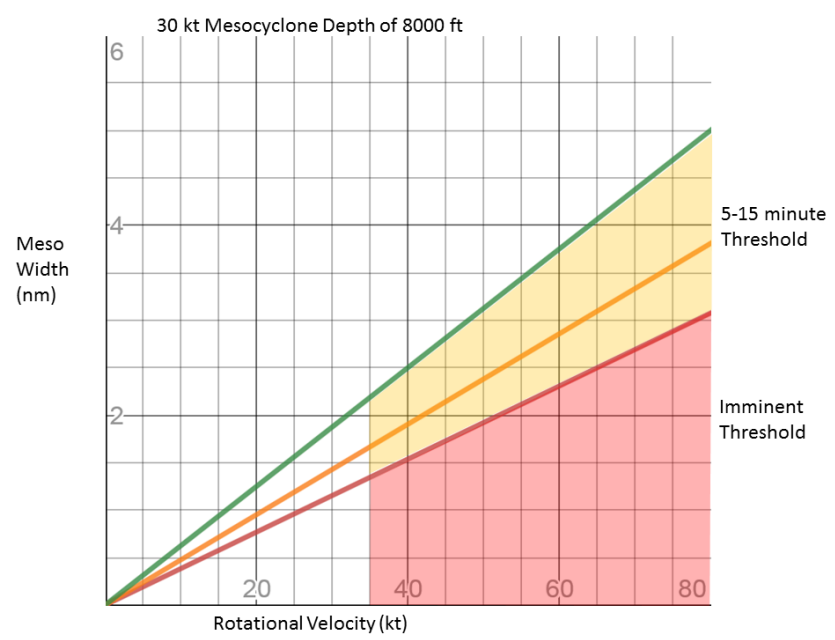

Figure 8. Same as Fig. 3 but for a mesocyclone depth of $2438 \mathrm{~m}(8000 \mathrm{ft})$.

was increased slightly to 75 instead of 60 , meaning a stronger combination of mesocyclone depth and rotational frequency was required (Table 18). Skill 


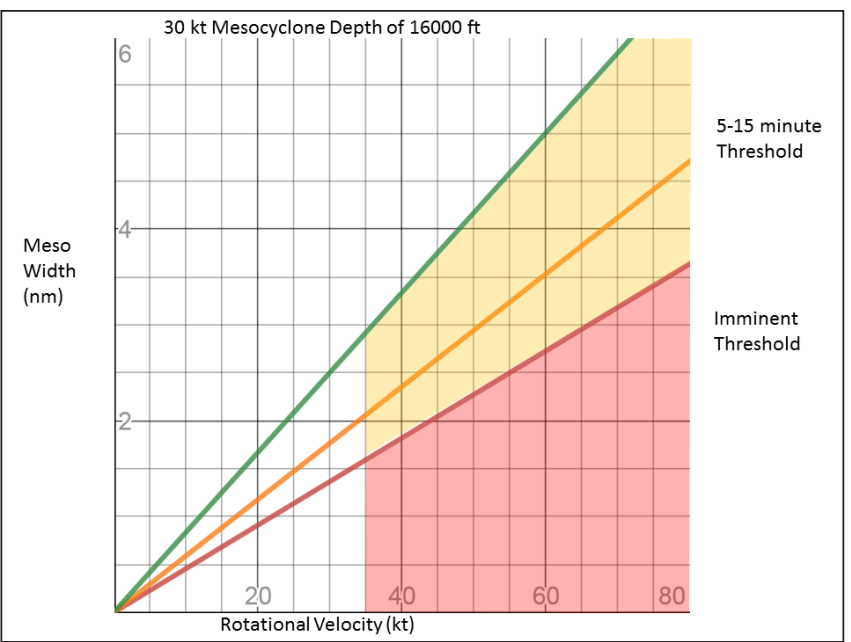

Figure 9. Same as Fig. 3 but for a mesocyclone depth of $4876 \mathrm{~m}(16000 \mathrm{ft})$.

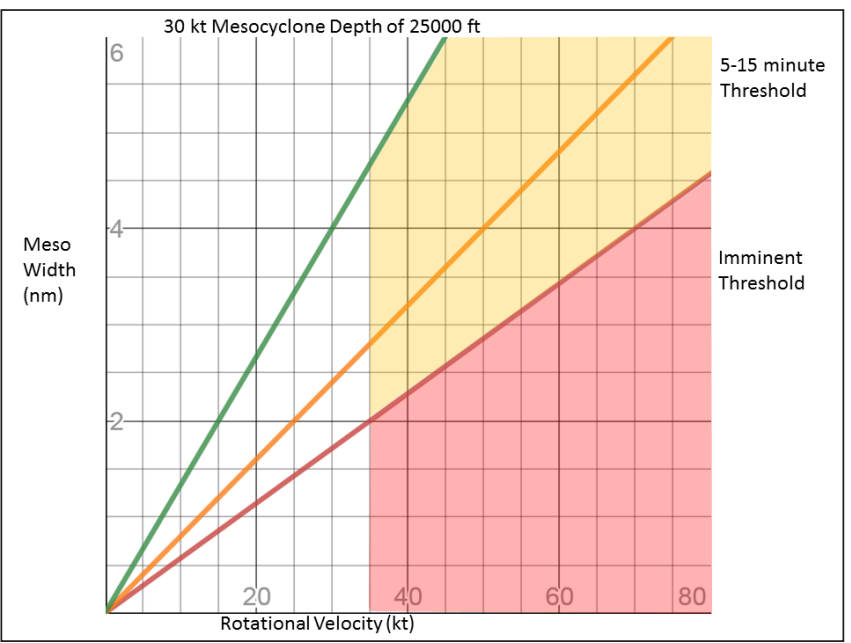

Figure 10. Same as Fig. 3 but for a mesocyclone depth of $7620 \mathrm{~m}(25000 \mathrm{ft})$.

was lower overall, but supported the general idea of STPP1-3 exceeding thresholds of significance for being associated with longer-lived significant tornadoes. This is an important area for future study, particularly for when to make catastrophic tag decisions for specific population centers that may be 10-15 min downstream of a significant tornado.

\section{d. Precursor signals for significant QLCS tornado events}

Bow echo and QLCS mesovorticies and tornadoes are developed and maintained by fundamentally different processes than supercell mesocyclones and tornadoes (Atkins and St. Laurent 2009). They do

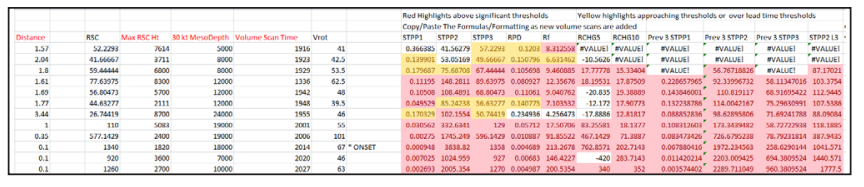

Figure 11. Example of a spreadsheet used for real-time tracking of multiple variables. The user enters variables in the four left columns for each VS, and significant thresholds are highlighted in the columns to the right.

share a commonality, however, in that there is often detectable mesocyclone/storm-scale rotation present when these events occur. Therefore, it is reasonable to suspect that some of the same detection and prediction methods that work for supercell significant tornadoes would work for QLCS significant tornadoes. After testing all of the parameters that showed significance in supercells, this does not appear to be the case. Table 19 shows the results of STPP3, for example, being applied to the full volumetric dataset of the QLCS/MCV events selected for this study. While the diagnostic capability of rotational velocity/speed for ongoing tornadoes persisted, the predictive skill was essentially zero. Similar trends were present on all other tests, including the depth of the mesocyclone, the combination of rotational frequency/speed with the depth of the mesocyclone, the height of the highest $V_{\text {rot }}$ value, and the various tests involving only the SAILS data. This provides further evidence that processes leading to significant QLCS tornadoes are particularly difficult to detect in advance using WSR-88D velocity features, even more so than supercell significant tornadoes.

This may explain some of the challenges apparent in NWS warning statistics for significant QLCS tornadoes. Techniques - such as the three-ingredients method (Schaumann and Przybylinski 2012) - that focus on the location of cold pool/shear balance regimes, line-normal $0-3-\mathrm{km}$ shear, and surges or bows in the line show promise and have been included in WDTD training (WDTD 2018c). These techniques, however, have not been quantified yet in the literature across a broad spectrum for use in discriminating between significant tornadoes and nonsignificant tornadoes. Future studies are needed to apply, and quantify the skill of, these techniques and develop any others that may show promise in recognizing developing QLCS/ MCV significant tornadoes with some degree of skill and lead time. 
Table 15. Same as Table 6, but using only SAILS $V_{\text {rot }}$ values

\begin{tabular}{|c|c|c|c|c|c|c|}
\hline \multicolumn{5}{|c|}{ SAILS 0.5-degree Vrot at a given strength and time relative to the onset of significant tornado damage } \\
\hline $\begin{array}{c}\mathbf{4 5} \mathbf{k t} \\
\text { at onset }\end{array}$ & POD & FAR & CSI & HSS & $\chi^{2}$ & N \\
\hline $\begin{array}{c}\mathbf{4 5} \text { kt one } \\
\text { cut Prior }\end{array}$ & 0.691 & 0.253 & 0.560 & 0.409 & 26.31 & 150 \\
\hline $\begin{array}{c}\mathbf{4 0} \text { kt two } \\
\text { cuts prior }\end{array}$ & 0.583 & 0.319 & 0.457 & 0.207 & 7.52 & 148 \\
\hline $\begin{array}{c}\mathbf{4 0} \text { kt three } \\
\text { cuts prior }\end{array}$ & 0.583 & 0.416 & 0.411 & 0.167 & 4.00 & 149 \\
\hline
\end{tabular}

Table 16. Same as Table 6 , but applying RSC to only the $0.5^{\circ}$ data, which includes SAILS data.

\begin{tabular}{|c|c|c|c|c|c|c|}
\hline \multicolumn{7}{|c|}{$\begin{array}{c}\text { RSC using only the } 0.5^{\circ} \text { slice (including SAILS) at a given strength and time relative to the onset of } \\
\text { significant tornado damage }\end{array}$} \\
\hline & POD & FAR & CSI & HSS & $\chi^{2}$ & $\mathbf{N}$ \\
\hline $\begin{array}{l}40 \text { at } \\
\text { onset }\end{array}$ & 0.714 & 0.266 & 0.567 & 0.428 & 19.05 & 150 \\
\hline $\begin{array}{l}35 \text { one } \\
\text { slice prior }\end{array}$ & 0.595 & 0.253 & 0.495 & 0.220 & 17.42 & 149 \\
\hline $\begin{array}{l}35 \text { two } \\
\text { slices prior }\end{array}$ & 0.597 & 0.388 & 0.433 & 0.182 & 5.22 & 148 \\
\hline $\begin{array}{l}30 \text { three } \\
\text { slices prior }\end{array}$ & 0.543 & 0.493 & 0.356 & 0.063 & 1.33 & 149 \\
\hline
\end{tabular}

Table 17. Same as Table 6 , but applying the change in RSC using only $0.5^{\circ}$ data including SAILS.

\begin{tabular}{l}
\multicolumn{8}{|c|}{$\Delta$ RSC using only $\mathbf{0 . 5 ^ { \circ }}$ slice data (Including SAILS) at a given strength and time relative to the onset of } \\
significant tornado damage \\
\hline
\end{tabular}

\section{Conclusions}

This study intended to evaluate various radar velocity-based techniques for skill in differentiating between significant tornado and weak/nontornadic events across storm modes. A key focus of this work is to utilize data that would be available in real-time to forecasters for making warning decisions. A total of 145 significant tornado events were selected mostly from 2017 to early 2019. An additional 145 NIL cases or weak/nontornadic events were selected in part from the database used in the S15 and T17 studies, with values of high $V_{\text {rot }}$ selected preferentially to examine what other characteristics might stand out.

A number of parameters are found to be skillful for supercells. These parameters centered on strength of $V_{\text {rot }}$ at the location of maximum volumetric rotational speed, the height of that peak, volumetric rotational speed, frequency, and period and depth of the $\geq 15.43$ $\mathrm{m} \mathrm{s}^{-1}$ (30 kt) mesocyclone. Several parameters were reassessed from G16 and found to maintain similar skill as was presented in that paper.

The combination of multiple parameters presented the strongest predictive skill, particularly those 
Table 18. Contingency table and skill scores for significant values of STPP3 in identifying storms that produced significant damage for more than two VSs.

Combination of average of last two VSs angular speed and the depth of the storm mesocyclone (STPP3) in storms producing significant damage for more than two VSs

\begin{tabular}{l|c|c} 
& $\geq \mathbf{7 5}$ & $<\mathbf{7 5}$ \\
$>\mathbf{1 0}$ min of EF2+ damage & 40 & 10 \\
$<\mathbf{1 0}$ min of EF2+ damage & 12 & 16
\end{tabular}

POD: 0.769 FAR: 0.200 CSI:0.646 HSS:0.377 $\chi^{2}: 18.238$

Table 19. Same as Table 6, but for using STPP3 at attempting to identify significant tornado events in QLCS/MCV storm types.

\begin{tabular}{|c|c|c|c|c|c|c|}
\hline \multicolumn{5}{|c|}{ STPP3 in discriminating significant, from weak/non tornado events in QLCS/MCV storm types } \\
\hline & POD & FAR & CSI & HSS & $\chi^{2}$ & N \\
\hline 40 at onset & 0.520 & 0.350 & 0.406 & 0.047 & 0.320 & 120 \\
\hline $\begin{array}{c}40 \text { one } \\
\text { VS prior }\end{array}$ & 0.523 & 0.433 & 0.373 & 0.034 & 0.302 & 120 \\
\hline $\begin{array}{c}\text { 40 two } \\
\text { VS prior }\end{array}$ & 0.532 & 0.583 & 0.304 & 0.042 & 0.314 & 120 \\
\hline
\end{tabular}

that measured rotational speed (via $V_{\text {rot }}$ strength and diameter) coupled with the depth of the parent mesocyclone. Multiple mathematical formulations suggest the combination of volumetric rotational speed and mesocyclone depth produce a skillful predictor of significant supercell tornado development in the VSs preceding significant tornado damage. Stronger rotational speed and deeper mesocyclones also were associated with tornadoes that produced significant damage for longer periods of time $(\geq 5 \mathrm{~min})$. The change in rotational speed from one VS to another also showed strong diagnostic skill. Nomograms and a spreadsheet are provided to aid in rapid operational assessment of these parameters.

It also was shown that the same parameters that work quite well in the supercell mode to discriminate tornado intensity in advance do not work with the QLCS/MCV storm mode. Storm maximum rotational speed, frequency, and period (and the height at which these occur), as well as the depth of the $\geq 15.43 \mathrm{~m} \mathrm{~s}^{-1}$ (30 kt) mesocyclone and various combinations of the preceding, showed little to no predictive skill in this storm mode.

The results of this study are intended to provide forecasters a more precisely quantified radar-based assessment of when the threat of a significant tornado is increasing. While there are still limitations, the window appears to be opening for NWS forecasters to provide enhanced wording - with lead time - to significant tornadoes, rather than operating from a purely diagnostic approach. Some promise of methods for determining whether a storm will continue to produce significant damage (a key consideration of IBWs), also was shown. Future work may be able to better refine this relationship, particularly with regard to "Warn-onForecast" type operations under development within NOAA and the National Severe Storms Laboratory (Karstens et al. 2018; Rothfusz et al. 2018). The results also show that QLCS/MCV significant tornadoes continue to present a significant predictability challenge and that additional effort in this area may help improve overall NWS tornado warning performance.

Acknowledgments: We thank Rich Thompson, Bryan Smith, and their collaborators for allowing us to use their extensive database of thunderstorm and tornado events that allowed for a significantly improved and less labor-intensive case selection process. Jim LaDue, Jami Boettcher, Todd Lindley, and Dr. Barbara Mayes-Boustead provided informal observations, reviews, and suggestions. JOM Editor Larry Hopper, Jason Schaumann, Dr. Nathan Dahl, and Jeremy Grams also provided thoughtful and thorough feedback through the formal review process. All are thanked for their effort and contributions that greatly improved the initial manuscript. 


\section{APPENDIX}

\section{Results of Additional Tests}

Tables A1-A2 present the results of the tests of RPD and Rf on the supercell dataset. All of these parameters showed statistical significance for differentiating, but had less overall skill, or lower lead times, than other methods and combinations.

Table 1. Skill scores for using angular period if used to provide warning of significant tornado events. $\chi^{2} \geq 9.210$ rejects the null hypothesis of theoretical distribution at $\mathrm{p} \geq 0.01$. $\mathrm{N}$ indicates the number of cases that met quality control criteria and were included in the analysis.

\begin{tabular}{|c|c|c|c|c|c|c|}
\hline \multicolumn{7}{|c|}{ RPD at given periods relative to the onset of significant tornado damage } \\
\hline & POD & FAR & CSI & HSS & $\chi^{2}$ & $\mathbf{N}$ \\
\hline $\begin{array}{c}\geq 0.12 \\
\text { at onset }\end{array}$ & 0.652 & 0.270 & 0.525 & 0.341 & 21.31 & 170 \\
\hline $\begin{array}{l}\geq 0.16 \text { one } \\
\text { VS Prior }\end{array}$ & 0.589 & 0.369 & 0.438 & 0.196 & 7.16 & 170 \\
\hline $\begin{array}{l}\geq 0.16 \text { two } \\
\text { VS prior }\end{array}$ & 0.555 & 0.611 & 0.295 & 0.070 & 1.74 & 170 \\
\hline $\begin{array}{l}\geq 0.16 \text { three } \\
\text { VS prior }\end{array}$ & 0.579 & 0.477 & 0.379 & 0.147 & 6.34 & 170 \\
\hline
\end{tabular}

Table 2. Same as Table A1, but for the rotational frequency of the given periods.

\begin{tabular}{|c|c|c|c|c|c|c|}
\hline \multicolumn{7}{|c|}{ Angular frequency at given periods relative to the onset of significant tornado damage $\left(R_{f}\right)$} \\
\hline & POD & FAR & CSI & HSS & $\chi^{2}$ & $\mathbf{N}$ \\
\hline 7 at onset & 0.651 & 0.188 & 0.565 & 0.376 & 32.08 & 170 \\
\hline $\begin{array}{l}5 \text { one } \\
\text { VS Prior }\end{array}$ & 0.594 & 0.250 & 0.497 & 0.238 & 21.25 & 170 \\
\hline
\end{tabular}




\section{REFERENCES}

Andra, Jr., D. L., 1997: The origin and evolution of the WSR88D mesocyclone recognition nomogram. Preprints, 28th Conf. on Radar Meteorology, Austin, TX, Amer. Meteor. Soc., 364-365.

Atkins, N. T., and M. St. Laurent, 2009: Bow echo mesovorticies. Part II: Their genesis. Mon. Wea. Rev., 137, 1514-1532, Crossref.

Brotzge, J. A., S. E. Nelson, R. L. Thompson, and B. T. Smith, 2013: Tornado probability of detection and lead time as a function of convective mode and environmental parameters. Wea. Forecasting, 28, 1261-1276, Crossref.

Brown, R. A., L. R. Lemon, and D. W. Burgess, 1978: Tornado detection by pulsed Doppler radar. Mon. Wea. Rev., 106, 29-38, Crossref.

, V. T. Wood, and D. Sirmans, 2002: Improved tornado detection using simulated and actual WSR-88D data with enhanced resolution. J. Atmos. Oceanic Technol., 19, 1759-1771, Crossref.

Burgess, D. W., M. A. Magsig, J. Wurman, D. C. Dowell, and Y. Richardson, 2002: Radar observations of the 3 May 1999 Oklahoma City tornado. Wea. Forecasting, 17, 456-471, Crossref.

Casteel, M. A., 2016: Communicating increased risk: An empirical investigation of the National Weather Service's impact-based warnings. Wea. Climate Soc., 8, 219-232, Crossref.

2018: An empirical assessment of impact based tornado warnings on shelter in place decisions. Int. J. Disaster Risk Reduct., 30, 25-33, Crossref.

Cohen, A. E., J. B. Cohen, R. L. Thompson, B. T. Smith, 2018: Simulating tornado probability and tornado wind speed based on statistical models. Wea. Forecasting, 33, 1099-1108, Crossref.

Dahl, N. A., and D. S. Nolan, 2018: Using high-resolution simulations to quantify errors in radar estimates of tornado intensity. Mon. Wea. Rev, 146, 2271-2296, Crossref.

Daintith, J., 2009: A Dictionary of Physics. 6th ed. Oxford University Press, $616 \mathrm{pp}$.

Doviak, R. J., and D. S. Zrnić, 2006: Doppler Radar and Weather Observations. 2nd ed. Dover Publications, 592 pp.

Dowell, D. C., C. R. Alexander, J. M. Wurman, and L. J. Wicker, 2005: Centrifuging of hydrometeors and debris in tornadoes: Radar-reflectivity patterns and windmeasurement errors. Mon. Wea. Rev., 133, 1501-1524, Crossref.

Falk, K., 1997: Techniques for issuing severe thunderstorm and tornado warnings with the WSR-88D Doppler radar. NOAA Tech. Memo. SR-185, 44 pp. [Available online at repository.library.noaa.gov/view/noaa/6360.]

, and W. Parker, 1998: Rotational shear nomogram for tornadoes. Preprints, 19th Conf. on Severe Local Storms,
Minneapolis, MN, Amer. Meteor. Soc., 733-735.

Gibbs, J. G., 2016: A skill assessment of techniques for realtime diagnosis and short-term prediction of tornado intensity using the WSR-88D. J. Operational Meteor., 4 (13), 170-181, Crossref.

Heidke, P., 1926: Calculation of the success and goodness of strong wind forecasts in the storm warning service. Geogr. Ann., 8, 301-349, Crossref.

Karstens, C. D., and Coauthors, 2018: Development of a human-machine mix for forecasting severe convective events. Wea. Forecasting, 33, 715-737, Crossref.

Kingfield, D. M., and J. G. LaDue, 2015: The relationship between automated low-level velocity calculations from the WSR-88D and maximum tornado intensity determined from damage surveys. Wea. Forecasting, 30, 1125-1139, Crossref.

Lemon, L. R., and C. A. Doswell III, 1979: Severe thunderstorm evolution and mesocyclone structure as related to tornadogenesis. Mon. Wea. Rev. 107, 11841197, Crossref.

Naegle, D. E., and J. E. Trainor, 2012: Geographic specificity, tornadoes, and protective action. Wea. Climate Soc., $\mathbf{4}$, 145-155, Crossref.

NWS, cited 2019a: Joplin, Missouri, tornado $\neg$ May 22, 2011. NWS Central Region service assessment, $41 \mathrm{pp}$. [Available online at www.weather.gov/media/ publications/assessments/Joplin tornado.pdf.] , cited 2019b: National Weather Service instruction 10-511. WFO severe weather products specification, 58 pp. [Available online at www.nws.noaa.gov/directives/ sym/pd01005011curr.pdf.]

Piltz, S. F., and D. W. Burgess, 2009: The impacts on thunderstorm geometry and WSR-88D beam characteristics on diagnosing supercell tornadoes. Preprints, 34th Conf. on Radar Meteorology, Williamsburg, VA, Amer. Meteor. Soc., P6.18. [Available online at ams.confex.com/ams/34Radar/techprogram/ paper 155944.htm.]

Rao, C. R., 2002: Karl Pearson chi-square test: The dawn of statistical inference. Goodness-of-Fit Tests and Model Validity, C. Huber-Carol, N. Balakrishnan, M. S. Nikulin, and M. Mesbah, Eds., Birkhäuser, 9-24, CrossRef.

Ripberger, J. T., C. L. Silva, H. C. Jenkins-Smith, and M. James, 2015: The influence of consequence-based messages on public responses to tornado warnings. Bull. Amer. Meteor. Soc., 96, 577-590, Crossref.

Rothfusz, L. P., R. Schneider, D. Novak, K. KlockowMcClain, A. E. Gerard, C. Karstens, G. J. Stumpf, and T. M. Smith, 2018: FACETs: A proposed next-generation paradigm for high-impact weather forecasting. Bull. Amer. Meteor. Soc., 99, 2025-2043, Crossref.

Schaefer, J. T., 1990: The critical success index as an indicator of warning skill. Wea. Forecasting, 5, 570-575, Crossref.

Schaumann, J. S., and Przybylinksi, R. W., 2012: Operational application of $0-3 \mathrm{~km}$ bulk shear vectors in assessing 
QLCS mesovortex and tornado potential. Preprints, 26th Conf. on Severe Local Storms, Nashville, TN, Amer. Meteor. Soc., P9.10. [Available online at ams. confex.com/ams/26SLS/webprogram/Paper212008. html.]

Smith, B. T., R. L. Thompson, J. S. Grams, C. Broyles, and H. E. Brooks, 2012: Convective modes for significant severe thunderstorms in the contiguous United States. Part I: Storm classification and climatology. Wea. Forecasting, 27, 1114-1135, Crossref.

, R. L. Thompson, A. R. Dean, and P. T. Marsh, 2015: Diagnosing the conditional probability of tornado damage rating using environmental and radar attributes. Wea. Forecasting, 30, 914-932, Crossref.

Thompson, R. L., B. T. Smith, J. S. Grams, A. R. Dean, and C. Broyles, 2012: Convective modes for significant severe thunderstorms in the contiguous United States. Part II: Supercell and QLCS tornado environments. Wea. Forecasting, 27, 1136-1154, Crossref. , and Coauthors, 2017: Tornado damage rating probabilities derived from WSR-88D data. Wea. Forecasting, 32, 1509-1528, Crossref.

Toth, M., R. J. Trapp, J. Wurman, and K. A. Kosiba, 2013: Comparison of mobile-radar measurements of tornado intensity with corresponding WSR-88D measurements. Wea. Forecasting, 28, 418-426, Crossref.

Trapp, R. J., E. D. Mitchell, G. A. Tipton, D. W. Effertz, A. I. Watson, D. L. Andra Jr., and M. A. Magsig, 1999: Descending and nondescending tornadic vortex signatures detected by WSR-88Ds. Wea. Forecasting, 14, 625-639, Crossref.

WDTD, cited 2018a: Applied performance drills: Storm top divergence. [Available online at training.weather.gov/ wdtd/courses/rac/severe/apd-storm-top-div/story html5.html.] , cited 2018b: Impact based warning training. [Available online at training.weather.gov/wdtd/courses/ibw/.] , cited 2018c: QLCS mesovortex recognition for tornado warnings: Part 2. [Available online at training.weather. gov/wdtd/courses/woc/severe/qlcs/qlcs2/presentation. html.] , cited 2018d: RDA/RPG build 18.0 training. [Available online at training.weather.gov/wdtd/buildTraining/ build18/presentation/presentation html5.html.] , cited 2018e: Velocity dealiasing. [Available online at training.weather.gov/wdtd/courses/rac/principles/ dealiasing/presentation html5.html.]

Wood, V. T., and R. A. Brown, 1997: Effects of radar sampling on single-Doppler velocity signatures of mesocyclones and tornadoes. Wea. Forecasting, 12, 928-938, Crossref. 